\title{
Noninvasive ventilatory support does not facilitate recovery from acute respiratory failure in chronic obstructive pulmonary disease
}

\author{
F. Barbé, B. Togores, M. Rubí, S. Pons, A. Maimó, A.G.N. Agustí
}

\begin{abstract}
Noninvasive ventilatory support does not facilitate recovery from acute respiratory failure in chronic obstructive pulmonary disease. F. Barbé, B. Togores, M. Rubí, S. Pons, A. Maimó, A.G.N. Agustí. c)ERS Journals Ltd 1996.

ABSTRACT: This investigation evaluates, in a prospective, randomized and controlled manner, whether noninvasive ventilatory support (NIVS) with bilevel positive airway pressure (BiPAP) facilitates recovery from acute respiratory failure (ARF) in patients with chronic obstructive pulmonary disease (COPD).

Twenty four patients (mean age ( \pm SEM) $68 \pm 2$ yrs) with COPD (forced expiratory volume in one second (FEV1) at discharge $33 \pm 2 \%$ predicted), who attended the emergency room because of ARF ( $\mathrm{pH} 7.33 \pm 0.01$; arterial oxygen tension $\left(\mathrm{Pa}, \mathrm{O}_{2}\right)$ $6.0 \pm 0.2 \mathrm{kPa}$; arterial carbon dioxide tension $\left.\left(\mathrm{Pa}_{\mathrm{a}}, \mathrm{CO}_{2}\right) 7.9 \pm 0.3 \mathrm{kPa}\right)$, were initially randomized. Four out of the 14 patients $(29 \%)$ allocated to received NIVS did not tolerate it. Of the remaining 20 patients, 10 received NIVS with BiPAP in a conventional hospital ward during the first 3 days of hospitalization (two daytime sessions of $3 \mathbf{~ h}$ duration each). All 20 subjects were treated with oxygen, bronchodilators and steroids. On the first and third hospitalization days, before and $30 \mathrm{~min}$ after withdrawing oxygen therapy and/or BiPAP ventilatory support, we measured peak expiratory flow, arterial blood gas values, ventilatory pattern, occlusion pressure $(P 0.1)$, and maximal inspiratory (MIP) and maximal expiratory (MEP) pressures.

All patients were discharged without requiring tracheal intubation and mechanical ventilation. Hospitalization time was similar in both groups $(11.3 \pm 1.3$ vs $10.6 \pm 0.9$ days, control vs BiPAP, respectively). Arterial oxygenation, respiratory acidosis and airflow obstruction improved significantly throughout hospitalization in both groups. By contrast, the ventilatory pattern, P0.1, MIP and MEP did not change. NIVS with BiPAP did not cause any significant difference between groups.

We conclude that noninvasive ventilatory support with bilevel positive airway pressure does not facilitate recovery from acute respiratory failure in patients with chronic obstructive pulmonary disease. Furthermore, a substantial proportion of patients $(29 \%)$ do not tolerate noninvasive ventilatory support under these circumstances. From these results, we cannot recommend the use of noninvasive ventilatory support with bilevel positive airway pressure in the routine management of chronic obstructive pulmonary disease patients recovering from acute respiratory failure.
\end{abstract}

Eur Respir J., 1996, 9, 1240-1245.

\author{
Servei Pneumología, Hospital Univ, Son \\ Dureta, Palma de Mallorca, Spain. \\ Correspondence: A.G.N. Agustí \\ Servei de Pneumología \\ Hospital Univ. Son Dureta \\ 07014 Palma de Mallorca \\ Spain
}

Keywords: Bilevel positive airway pressure chronic obstructive pulmonary disease oxygen therapy respiratory Failure ventilatory Support

Received: 27 April 1995

Accepted after revision January 211996

Supported, in part, by Fondo de Investigaciones Sanitarias de la Seguridad Social (FIS 93/0860), ABEMAR and Carburos Metalicos SA.

Presented at the Annual Meeting of the European Respiratory Society held in Florence (Italy) in 1993.
Patients with chronic obstructive pulmonary disease (COPD) often require hospitalization because of acute exacerbations [1]. The standard medical treatment of acute respiratory failure (ARF) in patients with COPD includes oxygen, bronchodilators and steroids [1]. Recently, there has been considerable interest in the use of noninvasive ventilatory support (NIVS) in ARF [2]. In a study with historically matched controls, BROCHARD et al. [3] showed that inspiratory assistance with a face mask was effective in preventing tracheal intubation in ARF. More recently, BотT et al. [4] conducted a randomized controlled study and suggested that NIVS should be offered to COPD patients with ARF if conventional therapy does not produce a prompt response. In practice, however, most COPD patients with ARF are successfully managed with conventional therapy and do not require intensive care control [1]. Whether or not NIVS can facilitate recovery in this much more common clinical scenario is presently undefined [2]. In theory, NIVS can be helpful by enhancing pulmonary gas exchange, ventilatory control and/or respiratory muscle function $[1,2,5]$.

To assess the role of NIVS in the routine management of COPD patients recovering from ARF, we designed a prospective, randomized, controlled investigation, and decided a priori: 1 ) to use bi-level positive airway pressure (BiPAP) support, since this type of NIVS is generally better tolerated than other systems [2];2) to conduct the whole study in a conventional ward, outside the intensive care setting; 3 ) to ventilate the patients only during the daytime, which should theoretically facilitate its clinical implementation because NIVS is a time-consuming procedure $[2,6]$, and nursing staff are more available 
during the day; and 4) to use a predefined ventilatory strategy of $6 \mathrm{~h} \cdot \mathrm{day}^{-1}$ (two sessions of $3 \mathrm{~h}$ each), during the first 3 days of hospitalization. Clinical experience and previous studies [4] have shown that the average duration of NIVS in this setting is about $7 \mathrm{~h} \cdot \mathrm{day}^{-1}$.

\section{Methods}

\section{Patients}

Twenty four consecutive male COPD patients, who attended the emergency room because of ARF, entered the study and were initially randomized. Mean age ( \pm SEM) was $68 \pm 2$ yrs. All patients were smokers $(68 \pm 4$ packyrs). All patients had severe respiratory failure (arterial oxygen tension $\left(\mathrm{Pa}_{\mathrm{a}} \mathrm{O}_{2}\right)$ breathing room air $\left.6.0 \pm 0.2 \mathrm{kPa}\right)$ with respiratory acidosis (arterial carbon dioxide tension $\left(P \mathrm{a}, \mathrm{CO}_{2}\right) 7.9 \pm 0.3 \mathrm{kPa}$; $\left.\mathrm{pH} 7.33 \pm 0.01\right)$. None of the patients showed clinical or radiological evidence of bacterial pneumonia, pleural effusion, left ventricular failure or nasal deformities. Table 1 shows the results of pulmonary function tests obtained at discharge. All patients had severe COPD, as shown by the degree of airflow obstruction, hyperinflation and air-trapping (table 1).

\section{Protocol}

The protocol was approved by the Local Ethics Committee. All patients (or their next of kin) gave informed consent after being fully informed of the purpose, characteristics and nature of the study. Within the first 12-48 $\mathrm{h}$ of hospitalization, patients were transferred to the ward of the respiratory unit of our institution, where the investigation was carried out. During the first 3 days of their arrival in the ward, all patients received aerosolized salbutamol (5 $\mathrm{mg}$ q.i.d.) and i.v. prednisolone (40 $\mathrm{mg}$ t.i.d.); drugs were later tapered individually. Controlled oxygen therapy (Venturi mask) was used throughout to maintain arterial oxygen saturation $\left(\mathrm{Sa}, \mathrm{O}_{2}\right)>90 \%$ (Criticare, USA). Half of the patients were also randomly assigned to receive ventilatory support with BiPAP (Respironics, USA). BiPAP was applied through a nasal mask (Respironics, USA), for $3 \mathrm{~h}$ in the morning and $3 \mathrm{~h}$ in the afternoon,

Table 1. - Anthropometric data and pulmonary function results (measured at discharge)

\begin{tabular}{lcc}
\hline & Control & BiPAP \\
\hline Age yrs & $65 \pm 3$ & $70 \pm 2$ \\
BMI $\mathrm{kg} \cdot \mathrm{m}^{-2}$ & $25.2 \pm 1.1$ & $24.9 \pm 1.3$ \\
FEV $\%$ pred & $30 \pm 3$ & $36 \pm 4$ \\
FEV1/FVC \% & $40 \pm 2$ & $48 \pm 3$ \\
TLC \% pred & $117 \pm 7$ & $102 \pm 5$ \\
RV \% pred & $191 \pm 12$ & $166 \pm 11$ \\
RV/TLC \% & $65 \pm 2$ & $64 \pm 2$ \\
TL,CO \% pred & $71 \pm 8$ & $90 \pm 6$ \\
\hline
\end{tabular}

BiPAP: bilevel positive airway pressure; BMI: body mass index; FEV1: forced expiratory volume in one second; FVC: forced vital capacity; TLC: total lung capacity; RV: residual volume; TL,CO: transfer factor of the lungs for carbon monoxide; \% pred: percentage of predicted value. No variable was significantly different between groups. during the first 3 days of hospitalization. Adaptation to BiPAP was supervised at the bedside by one of the authors. The patients were instructed to keep the mouth closed, in order to avoid air leaks. Inspiratory pressure was set to the maximum tolerated value in each patient $(14.8 \pm 0.5$ $\mathrm{cmH}_{2} \mathrm{O}$ ); expiratory pressure was always $5 \mathrm{cmH}_{2} \mathrm{O}$. During BiPAP ventilation, oxygen $\left(2-4 \mathrm{~L} \cdot \mathrm{min}^{-1}\right)$ was given through the lateral port of the nasal mask to maintain an $\mathrm{Sa}, \mathrm{O}_{2}>90 \%$ (Criticare, USA). During the 3 days of BiPAP support, the initial ventilatory regimen was not modified.

\section{Measurements}

Measurements were obtained at the bedside on the first and third day of hospitalization, both before and $30 \mathrm{~min}$ after withdrawing oxygen therapy and/or BiPAP support. The patient lay in a semirecumbent position and breathed room air through a one-way valve (Hans Rudolph, USA). A computer-controlled system allowed on-line monitoring and simultaneous recording of airflow (Pneumotachograph Jaegger, Wurtzburg, Germany) and mouth pressure (Siebel, Barcelona, Spain). From the flow signal, the following values were obtained: the respiratory rate $(f R)$, inspiratory time $(t \mathrm{I})$, total respiratory time $(t$ tot $)$ and the duty cycle $(t \mathrm{I} / t$ tot $)$ ratio. The expired gas was collected in a nondiffusable gas bag (Hans Rudolph, USA) for measurement of total minute ventilation $\left(V^{\prime} \mathrm{E}\right)$. From these data, tidal volume $(V \mathrm{~T})\left(V \mathrm{~T}=V^{\prime} \mathrm{E} / f \mathrm{R}\right)$ and mean inspiratory flow $(V \mathrm{~T} / t \mathrm{I})$ were calculated. From the pressure signal recorded at the mouth, maximal inspiratory (MIP) and expiratory pressures (MEP) from residual volume (RV) and total lung capacity (TLC), respectively were measured [7], and also the occlusion pressure $\left(P_{0.1}\right)$ using the standard occlusion technique [7]. Airflow obstruction was evaluated using peak flow measurements (Wright peak flow meter, UK). Shortness of breath was assessed with the Borg [8] scale. Arterial blood gas values were measured in a sample obtained anaerobically by direct punction of the radial artery, after local anaesthesia (Instrumentation Laboratories BG3, Izasa, Barcelona, Spain). The alveolar-arterial oxygen gradient $\left(P(\mathrm{~A}-\mathrm{a}), \mathrm{O}_{2}\right)$ was calculated according to the standard formula [7] $\left(P(\mathrm{~A}-\mathrm{a}), \mathrm{O}_{2}=\left(\left(\left(\right.\right.\right.\right.$ barometric pressure-47)*0.21) $\left.-\left(\mathrm{Pa}, \mathrm{CO}_{2} / \mathrm{R}\right)\right)-$ $\left.P \mathrm{a}, \mathrm{O}_{2}\right)$. The respiratory quotient $(\mathrm{R})$ was assumed to be 0.8. A complete set of measurements included, in this order, measures of shortness of breath, ventilatory pattern, $P_{0.1}$, arterial blood gas values, peak flow, MIP and MEP. A set was obtained for each patient on the first and third day of hospitalization (morning and evening), and at discharge.

Patients were discharged following the clinical judgement of the physician in charge, who was not blind to the presence or absence of BiPAP. At discharge, forced spirometry, lung volumes and transfer factor of the lungs for carbon monoxide (TL,CO) (W.E. Collins, USA) were measured. Reference values were from a Mediterranean population [9].

\section{Statistical analysis}

Data are presented as mean \pm SEM. Anthropometric variables and those measured at hospital discharge (table 1) 


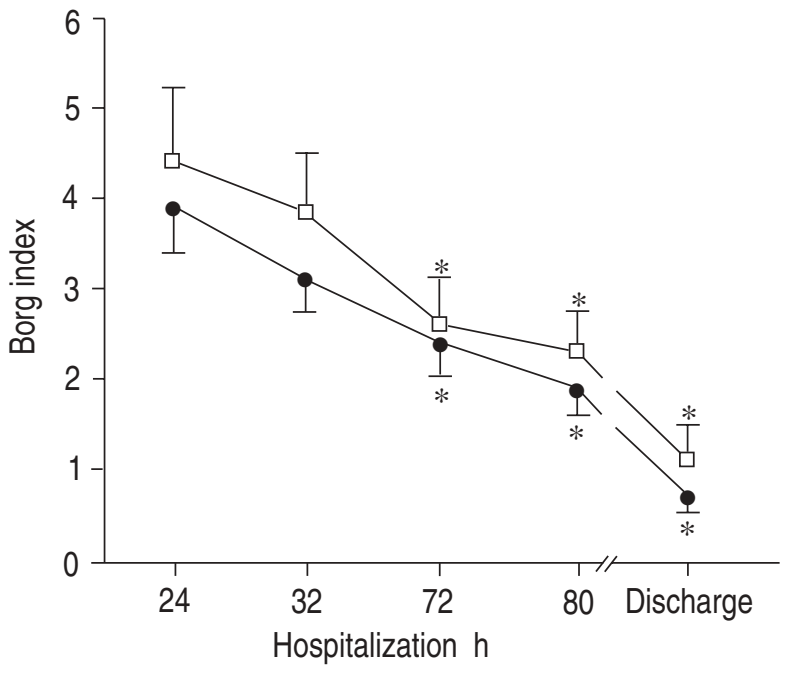

Fig. 1. - Evolution (mean \pm sem) of the Borg index throughout hospitalization. Higher scores indicate more dyspnoea. There was a significant decrease of dyspnoea throughout hospitalization $(\mathrm{p}<0.001)$. However, differences between groups were not significant. Asterisks indicate significance of differences within groups, compared to baseline $(24 \mathrm{~h}) . \square-$ : control; $\longrightarrow$ : bilevel positive airway pressure (BiPAP).

in each group (control $v s$ BiPAP) were compared using an unpaired t-test. The analysis of the effects of BiPAP on the variables measured sequentially throughout hospitalization was made using a two-way analysis of variance (ANOVA) followed by a post-hoc contrast analysis (Tukey test). A p-value lower than 0.05 was considered to be significant.

\section{Results}

\section{Clinical data}

Clinical evolution throughout hospitalization was adequate in all patients. All patients were successfully discharged from hospital, and none required tracheal intubation and invasive mechanical ventilation. Four out of the 14 patients $(29 \%)$ initially randomized to receive BiPAP did not tolerate NIVS; three due to claustrophobia, and the one unable to co-operate because of anxiety. These four patients were excluded from further analysis. Therefore, the effects of NIVS during recovery from ARF were investigated by comparing two groups of 10 patients each.

Mean age and body mass index (BMI) were similar in the control and treatment groups (table 1). Theophylline serum levels at entrance were not different between groups (1.4 \pm 0.7 (control) vs $2.8 \pm 1.2 \mathrm{mg} \cdot \mathrm{dL}^{-1}$ (BiPAP). Shortness of breath decreased significantly throughout hospitalization $(\mathrm{p}<0.001)$, but differences between groups were not significant (fig. 1). Hospitalization time was not different between groups $(11.3 \pm 1.3$ vs $10.6 \pm 0.9$ days, control $v s$ BiPAP).

\section{Physiological data}

$\mathrm{Pa}_{\mathrm{a}} \mathrm{O}_{2}$ increased steadily throughout hospitalization in both groups (fig. 2a). As a result, $P_{\mathrm{a}, \mathrm{O}_{2}}$ measured at 72 ,
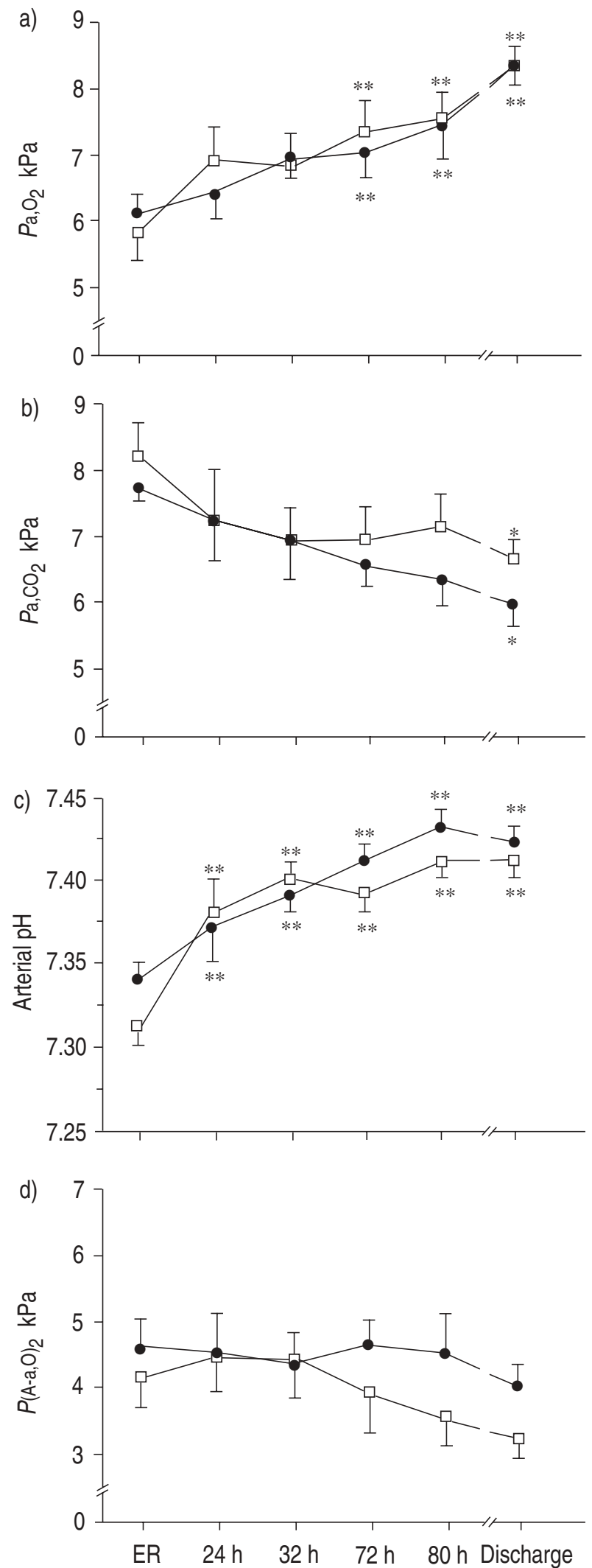

Fig. 2. - Evolution through hospitalization (mean \pm SEM) of: a) arterial oxygen tension $\left.\left(\mathrm{Pa}_{\mathrm{a}} \mathrm{O}_{2}\right) ; \mathrm{b}\right)$ arterial carbon dioxide tension $\left(\mathrm{Pa}_{\left.\mathrm{a}, \mathrm{CO}_{2}\right)}\right.$; c) arterial $\mathrm{pH}$; and $\mathrm{d})$ alveolar to arterial oxygen gradient $\left(\mathrm{P}(\mathrm{A}-\mathrm{a}), \mathrm{O}_{2}\right)$. Asterisks indicate significance of differences within groups, compared to measures in the emergency room (ER) on admission. *: $\mathrm{p}<0.05$; **: $\mathrm{p}<0.001$. $\square \square$ : controls; $\longrightarrow-$ : bilevel positive airway pressure (BiPAP). For further explanation, see text. 
$80 \mathrm{~h}$ and at discharge was higher $(\mathrm{p}<0.001)$ than in the emergency room (fig. 2a). There were no significant differences between groups. $P \mathrm{a}, \mathrm{CO}_{2}$ decreased with time in both groups (fig. 2b). At discharge $\mathrm{Pa}_{\mathrm{a}} \mathrm{CO}_{2}$ was significantly lower $(\mathrm{p}<0.05)$ than in the emergency room (fig. 2b). As shown in fig. $2 \mathrm{~b}$, patients treated with BiPAP appeared to have a faster fall in arterial hypercapnia than the control group. However, differences between groups were small in absolute terms $( \pm 0.5 \mathrm{kPa})$ and failed to reach statistical significance. Arterial $\mathrm{pH}$ improved significantly during the first $24 \mathrm{~h}$ of hospitalization in both groups (fig. 2c). Differences between groups were not significant. Interestingly, the $P(\mathrm{~A}-\mathrm{a}), \mathrm{O}_{2}$ gradient did not change significantly throughout hospitalization in any group (fig. 2d).

Peak flow values increased $(\mathrm{p}<0.05)$ with time and to the same extent in both groups (table 2). Neither total $V^{\prime} \mathrm{E}$ nor $f \mathrm{R}, V \mathrm{~T}$, mean inspiratory flow $(V \mathrm{~T} / t \mathrm{I})$ or the ratio $t \mathrm{I} / t$ tot changed significantly throughout hospitalization (table 2). Overall, the occlusion pressure $\left(P_{0.1}\right)$ was higher than normal, as previously reported in stable COPD patients $[10,11]$. However, it did not decrease with time nor was it influenced by BiPAP (table 2). MIP and MEP did not change throughout hospitalization in any group (table 3).

\section{Discussion}

The aim of this investigation was to assess the effects of NIVS with BiPAP in the routine management of COPD patients recovering from ARF. To this end, we designed a prospective, controlled and randomized study, which was carried out entirely in a regular hospitalization ward. We did not find evidence that NIVS with BiPAP facilitates recovery in these patients.

In the past few years, there has been a tremendous interest in the use of NIVS during acute exacerbations of COPD. Several studies (most of them uncontrolled) have shown that NIVS can improve pulmonary gas exchange and avoid mechanical ventilation in ARF [3, 4, 12-18]. However, the vast majority of these patients are successfully managed in regular hospitalization wards and

Table 2. - Ventilatory data measured at 24, 32, 72 and $80 \mathrm{~h}$ from hospital admittance, and at discharge

\begin{tabular}{|c|c|c|c|c|c|}
\hline & $24 \mathrm{~h}$ & $32 \mathrm{~h}$ & $72 \mathrm{~h}$ & $80 \mathrm{~h}$ & Discharge \\
\hline \multicolumn{6}{|c|}{ Peak flow $\mathrm{L} \cdot \mathrm{min}^{-1}$} \\
\hline Control & $146 \pm 22$ & $151 \pm 24$ & $163 \pm 17$ & $178 \pm 25$ & $203 \pm 18 *$ \\
\hline BiPAP & $176 \pm 22$ & $171 \pm 22$ & $178 \pm 23$ & $166 \pm 27$ & $247 \pm 35^{*}$ \\
\hline \multicolumn{6}{|c|}{$V^{\prime} \mathrm{E} \quad \mathrm{L} \cdot \mathrm{min}^{-1}$} \\
\hline Control & $11.8 \pm 1.1$ & $12.2 \pm 1.0$ & $12.6 \pm 1.6$ & $14.0 \pm 1.7$ & $12.9 \pm 1.2$ \\
\hline BiPAP & $11.1 \pm 0.8$ & $11.3 \pm 1.2$ & $13.6 \pm 1.3$ & $12.9 \pm 0.8$ & $12.5 \pm 0.9$ \\
\hline \multicolumn{6}{|c|}{$f \mathrm{R}$ breaths $\cdot \mathrm{min}^{-1}$} \\
\hline Control & $24.0 \pm 3.0$ & $22.4 \pm 2.4$ & $22.5 \pm 2.4$ & $23.7 \pm 2.4$ & $20.8 \pm 1.7$ \\
\hline BiPAP & $23.7 \pm 1.5$ & $23.9 \pm 2.7$ & $24.2 \pm 2.3$ & $25.2 \pm 2.4$ & $23.1 \pm 1.4$ \\
\hline \multicolumn{6}{|l|}{$V \mathrm{~T} \mathrm{~mL}$} \\
\hline Control & $559 \pm 78$ & $603 \pm 77$ & $616 \pm 81$ & $614 \pm 60$ & $631 \pm 69$ \\
\hline BiPAP & $480 \pm 36$ & $498 \pm 41$ & $608 \pm 76$ & $561 \pm 71$ & $570 \pm 73$ \\
\hline \multicolumn{6}{|c|}{$V \mathrm{~T} / t \mathrm{I} \quad \mathrm{mL} \cdot \mathrm{s}^{-1}$} \\
\hline Control & $491 \pm 35$ & $532 \pm 48$ & $535 \pm 62$ & $582 \pm 62$ & $522 \pm 45$ \\
\hline BiPAP & $507 \pm 31$ & $486 \pm 38$ & $617 \pm 49$ & $575 \pm 30$ & $567 \pm 63$ \\
\hline \multicolumn{6}{|l|}{$t \mathrm{I} / t$ tot $\%$} \\
\hline Control & $0.40 \pm 0.02$ & $0.38 \pm 0.02$ & $0.40 \pm 0.02$ & $0.40 \pm 0.02$ & $0.40 \pm 0.02$ \\
\hline BiPAP & $0.37 \pm 0.01$ & $0.39 \pm 0.02$ & $0.37 \pm 0.02$ & $0.38 \pm 0.02$ & $0.39 \pm 0.02$ \\
\hline \multicolumn{6}{|c|}{$P 0.1 \quad \mathrm{cmH}_{2} \mathrm{O}$} \\
\hline Control & $2.6 \pm 0.3$ & $3.1 \pm 0.3$ & $3.2 \pm 0.5$ & $3.4 \pm 0.4$ & $2.5 \pm 0.5$ \\
\hline BiPAP & $2.9 \pm 0.3$ & $3.2 \pm 0.3$ & $3.4 \pm 0.5$ & $3.2 \pm 0.5$ & $3.5 \pm 0.5$ \\
\hline
\end{tabular}

$V^{\prime}$ E: minute ventilation (corrected for body temperature, atmospheric pressure and water saturation (BTPS) conditions [7]); $f$ R: respiratory frequency; $V \mathrm{~T} / t \mathrm{I}$ : mean inspiratory flow (tidal volume/inspiratory time); $t \mathrm{I} / t$ tot: percentage of total respiratory time used by inspiratory time; $P_{0.1}$ : occlusion pressure; BiPAP: bilevel positive airway pressure; Asterisks indicate significance of differences within groups, compared to baseline values $(24 \mathrm{~h})(*: \mathrm{p}<0.05)$. No variable was different between groups $(\operatorname{control} v s \mathrm{BiPAP})$ at any time throughout hospitalization.

Table 3. - Respiratory muscle function measured at 24, 32, 72 and $80 \mathrm{~h}$ from hospital admittance, and at discharge

\begin{tabular}{lccccc}
\hline & $24 \mathrm{~h}$ & $32 \mathrm{~h}$ & $72 \mathrm{~h}$ & $80 \mathrm{~h}$ & Discharge \\
\hline MIP cmH & $\mathrm{O}$ & & & & \\
Control & & & & & \\
BiPAP & $47.0 \pm 5.5$ & $52.4 \pm 8.0$ & $45.7 \pm 4.6$ & $45.4 \pm 6.1$ & $61.4 \pm 7.8$ \\
MEP & $34.4 \pm 5.5$ & $45.0 \pm 5.2$ & $50.6 \pm 7.3$ & $42.7 \pm 5.5$ & $52.4 \pm 6.2$ \\
Control & $96.9 \pm 13.6$ & $112.3 \pm 12.7$ & $117.3 \pm 13.5$ & $122.7 \pm 14.2$ & $125.8 \pm 17.0$ \\
BiPAP & $98.2 \pm 10.5$ & $92.7 \pm 4.9$ & $95.0 \pm 5.9$ & $97.2 \pm 4.5$ & $104.9 \pm 10.2$ \\
\hline
\end{tabular}

MIP: maximal inspiratory pressure; MEP; maximal expiratory pressure; BiPAP: bilevel positive airway pressure. No variable was significantly different between (control vs BiPAP) or within groups, at any time throughout hospitalization. 
do not require intensive care support $[1,2]$. To evaluate the role of NIVS in the routine management of COPD patients recovering from ARF, we prospectively compared two groups of patients with COPD attending the emergency room because of ARF. Both groups were similar in terms of age, BMI, arterial blood gas values at entrance and lung function tests at discharge (table 1 and fig. 2). In this investigation, we have evaluated the effects of a particular NIVS strategy ( $6 \mathrm{~h} \cdot \mathrm{day}^{-1}$ for 3 days); therefore, our results may not be readily extrapolated to other ventilatory paradigms (at night, all day), which may deserve future study. However, we consider that our investigation has explored an alternative which can be implemented in a general ward and, therefore, provides information of clinical relevance.

We did not measure arterial blood gases values during NIVS to assess the adequacy of ventilatory support. However, each patient was ventilated by systematically increasing inspiratory positive airway pressure (IPAP) to the maximum tolerated value and there was no capacity, therefore, to change the ventilatory paradigm (BiPAP $14.8 \pm 0.5 \mathrm{cmH}_{2} \mathrm{O}$, external positive airway pressure (EPAP) $5 \mathrm{cmH}_{2} \mathrm{O}$ ) in response to varying blood gas data. The ventilatory paradigm was very similar to that used by previous investigators $[12,17]$; thus, our conclusions regarding the impact of optimal tolerated NIVS on outcome appear valid.

In the current investigation, NIVS with BiPAP did not reduce hospitalization time, as compared to the control group. Breathlessness decreased throughout hospitalization similarly in both groups (fig. 1). As expected from previous clinical experience, the standard medical therapy of ARF [1] improved airway resistance (assessed through peak flow measurements (table 2)), arterial oxygenation and respiratory acidosis (fig. 2) throughout hospitalization in the control group. However, as shown in fig. 2, NIVS with BiPAP did not introduce any significant difference at any point in time (fig. 2). Other physiological parameters, such as the ventilatory pattern, the occlusive pressure (table 2) and the maximal respiratory pressures (table 3), were also not different between groups. Therefore, overall, our results show that NIVS with BiPAP (at least, under the particular ventilatory schedule employed in this investigation) does not facilitate clinical or physiological recovery in COPD patients hospitalized because of ARF. Furthermore, 4 out of the 14 patients $(29 \%)$ initially randomized to receive NIVS with BIPAP did not tolerate it. This is a substantial percentage of patients that argues against the routine use of NIVS in the management of ARF in patients with COPD.

Our investigation also provides information on the evolution of several important physiological variables during recovery from ARF in COPD. Although this was not the primary aim of our study, this is of potential interest because of the surprising paucity of data published in the literature on such a frequent and important clinical problem. An unexpected finding of our study was that the $P(\mathrm{~A}-\mathrm{a}), \mathrm{O}_{2}$ did not change throughout hospitalization (fig. 2). This suggests that the efficiency of the lung to exchange gases was not enhanced, despite medical treatment targeting the lung parenchyma (bronchodilators and steroids). Preliminary data by BARBERA et al. [19] supports this observation by showing that the degree of ventilation-perfusion inequality (evaluated using inert gases) also changes very little during ARF in COPD, and that modifications of cardiac output and oxygen uptake changes are the main determinants of arterial oxygenation in these patients [19].

On the other hand, minute ventilation did not change during recovery (table 2). This is in keeping with previous reports by AUBIER et al. [10]. However, these authors reported that during ARF patients with COPD normally exhibit a rapid shallow breathing pattern that tends to normalize during recovery [10]. By contrast, the ventilatory pattern in our patients did not change throughout hospitalization (table 2). Our baseline measurements of ventilatory pattern were obtained $24 \mathrm{~h}$ after hospitalization (table 2), not in the emergency room. Interestingly, available measurements of breathing frequency in the emergency room $(n=14)$ are significantly higher than those measured 24 h later $(34.5 \pm 2.1$ vs $23.8 \pm 1.6$, respectively; $\mathrm{p}<0.001)$. This suggests that the main ventilatory changes during ARF in COPD patients take place very early during recovery.

Finally, it is of note that MIP and MEP did not change with time (table 3 ). There are almost no data in the literature analysing the sequential evolution of respiratory muscle strength in ARF [20]. To our knowledge, our study is the first to report such measures. The lack of changes of MIP and MEP seen in our patients throughout hospitalization (table 3) suggests that strength failure of the respiratory muscles is not important during recovery in these patients. However, given that we did not measure respiratory muscle strength in the emergency room, the role of muscle dysfunction in the initial pathogenesis of ARF remains to be determined.

In summary, our investigation shows that ventilatory support with bilevel positive airway pressure does not facilitate recovery in patients with chronic obstructive pulmonary disease hospitalized because of acute respiratory failure. Furthermore, a substantial percentage of patients $(29 \%)$ do not tolerate noninvasive ventilatory support. Therefore, from these results we cannot recommend the routine use of noninvasive ventilatory support with bilevel positive airway pressure in the clinical management of acute respiratory failure in chronic obstructive pulmonary disease. Finally, our results contribute to a clarification of the role of various intra- and extrapulmonary factors that modulate gas exchange during recovery from acute respiratory failure in patients with chronic obstructive pulmonary disease.

\footnotetext{
Acknowledgements: The authors thank the nursing staff of the Servei of Pneumologia, Hospital Univ. Son Dureta (Palma Mallorca, Spain) for their help in the study.
}

\section{References}

1. Schmidt GA, Hall JB. Acute on chronic respiratory failure: assessment and management of patients with COPD in the emergent setting. J Am Med Assoc 1989; 261: 3444-3453.

2. Meyer TJ, Hill NS. Noninvasive positive pressure ventilation to treat respiratory failure. Ann Intern Med 1994; 120: 760-770. 
3. Brochard L, Isabey D, Piquet J, et al. Reversal of acute exacerbations of chronic obstructive lung disease by inspiratory assistance with a face mask. $N$ Engl J Med 1990; 323: 1523-1530.

4. Bott J, Carroll MP, Conway JH, et al. Randomised controlled trial of nasal ventilation in acute ventilatory failure due to chronic obstructive airways disease. Lancet. 1993; 341: 1555-1557.

5. Putensen C, Räsänen J, Lopez F. Ventilation-perfusion distributions during mechanical ventilation with superimposed spontaneous breathing in canine lung injury. Am J Respir Crit Care Med 1994; 150: 101-108.

6. Chevrolet JC, Jolliet P, Abajo B, Toussi A, Louis M. Nasal positive pressure ventilation in patients with acute respiratory failure. Chest 1991; 100: 775-782.

7. Clausen JL, eds. Pulmonary function testing: guidelines and controversies. Equipment, Methods and Normal Values. Orlando, Grune \& Stratton Inc., 1984; pp. 1-338.

8. Borg GA. Psychophysical bases of perceived exertion. Med Sci Sports Exerc 1982; 14: 377-381.

9. Roca J, Sanchis J, Agustí-Vidal A, et al. Spirometric reference values for a Mediterranean population. Bull Eur Physiopathol Respir 1986; 22: 217-224.

10. Aubier M, Murciano D, Fournier M, Milic-Emili J, Pariente R, Derenne J. Central respiratory drive in acute respiratory failure of patients with chronic obstructive pulmonary disease. Am Rev Respir Dis 1980; 122: 191-200.

11. Howes TQ, Deane CR, Levin GE, Baudouin SV, Moxham J. The effects of oxygen and dopamine on renal and aortic blood flow in chronic obstructive pulmonary disease with hypoxemia and hypercapnia. Am J Respir Crit Care Med 1995; 151: 378-383.
12. Pennock BE, Kaplan PD, Carlin BW, Sabangan JS, Magovern JA. Pressure support ventilation with a simplified ventilatory support system administered with a nasal mask in patients with respiratory failure. Chest 1991; 100: 1371-1376.

13. Benhamou D, Girault C, Faure C, Portier F, Muir J-F. Nasal mask ventilation in acute respiratory failure; experience in elderly patients. Chest 1992; 102: 912-917.

14. Miro AM, Shivaram U, Hertig I. Continuous positive airway pressure in COPD patients in acute hypercapnic respiratory failure. Chest 1993; 103: 266-268.

15. Marino W. Intermittent volume-cycled mechanical ventilation via nasal mask in patients with respiratory failure due to COPD. Chest 1991; 99: 681-684.

16. Meduri GU, Abou-Shala N, Fox RC, Jones CB, Leeper $\mathrm{CV}$, Wundering RG. Noninvasive face mask mechanical ventilation in patients with acute hypercapnic respiratory failure. Chest 1991; 100: 445-454.

17. Wysocki M, Tric L, Wolff MA, Gertner J, Millet H, Herman B. Noninvasive pressure support ventilation in patients with acute respiratory failure. Chest 1993; 103: 907-913.

18. Elliott MW, Steven MH, Phillips GD, Branthwaite MA. Noninvasive mechanical ventilation for acute respiratory failure. $\mathrm{Br}$ Med $J$ 1990; 300: 358-360.

19. Barberá JA, Félez MA, Roca J, Ferrer A, Wagner PD, Rodriguez-Roisín R. Gas exchange status during acute exacerbations of chronic obstructive pulmonary disease (COPD). Am J Respir Crit Care Med 1994; 149: A1010 (Abstract).

20. Gallagher CG. Respiratory steroid myopathy (Editorial). Am J Respir Crit Care Med 1994; 150: 4-6. 